\title{
Proposed Chronology of the Western Zhou Dynasty
}

\begin{tabular}{|c|c|}
\hline King Wen & I o99 $/ 5^{6}-$ I $05^{\circ}$ B.C. ${ }^{a}$ \\
\hline King $W u$ & $1049 / 45^{-1043}$ \\
\hline Duke of Zhou & $1042-1036$ \\
\hline King Cheng & I $042 / 35-$ I 006 \\
\hline King Kang & I $005 / 3-978$ \\
\hline King Zhao & $977 / 75-957$ \\
\hline King Mu & $95^{6-9 \text { I } 8}$ \\
\hline King Gong & $9^{17} /$ I $_{5}-900$ \\
\hline King Yihb & $899 / 97-873$ \\
\hline King Xiao & $872 ?-866$ \\
\hline King $\mathrm{Yi}_{\mathrm{i}}$ & $865-858$ \\
\hline King Li & $857 / 53-84^{2} / 28$ \\
\hline Gong $\mathrm{He}$ & $84 I-828$ \\
\hline King Xuan & $827 / 25-782$ \\
\hline King You & $78 \mathrm{I}-77 \mathrm{I}$ \\
\hline
\end{tabular}

NOTE: For a discussion of this chronology, see Appendix 3, pp. 217-287.

a Reign dates for the various Zhou kings are all in years before the common era, and the notation B.c. will be omitted hereafter.

'Throughout this book, the name of this king, $Y i$ 憼 (read in the fourth, or falling, tone) is romanized $Y$ ih to differentiate it from the name of his son, $Y_{i}$ 费 (read in the second tone), which is romanized as $\mathrm{Yi}$. 
This page intentionally left blank 